\title{
Synthetic Pathway Determines the Non-equilibrium Crystallography of Li- and Mn-rich Layered Oxides
}

Ashok S. Menon ${ }^{1}$, Seda Ulusoy ${ }^{2}$, Dickson O. Ojwang ${ }^{1}$, Lars Riekehr ${ }^{1}$, Christophe Didier ${ }^{3,4}$, Vanessa K. Peterson $^{3,5}$, Germán Salazar-Alvarez ${ }^{2}$, Peter Svedlindh ${ }^{2}$, Kristina Edström ${ }^{1}$, Cesar Pay Gomez ${ }^{1}$ and William R. Brant ${ }^{1 *}$

${ }^{1}$ Department of Chemistry-Ångström Laboratory, Uppsala University, Box 538, SE-75121 Uppsala, Sweden

${ }^{2}$ Department of Materials Science and Engineering, Uppsala University, Box 35, SE-75103, Uppsala, Sweden

${ }^{3}$ Australian Centre for Neutron Scattering, Australian Nuclear Science and Technology Organization, Locked Bag 2001, Kirrawee DC, New South Wales 2232, Australia

${ }^{4}$ School of Chemistry, University of New South Wales, Sydney 2052, Australia

${ }^{5}$ Institute for Superconducting \& Electronic Materials, Faculty of Engineering, University of Wollongong, Wollongong 2522, Australia 


\begin{abstract}
$\underline{\text { Abstract }}$
Li- and Mn-rich layered oxides show significant promise as electrode materials for future Li-ion batteries. However, accurate descriptions of its crystallography remain elusive, with both single-phase solid solution and multi-phase structures being proposed for high performing materials such as $\mathrm{Li}_{1.2} \mathrm{Mn}_{0.54} \mathrm{Ni}_{0.13} \mathrm{Co}_{0.13} \mathrm{O}_{2}$. Herein, we report the synthesis of single- and multi-phase variants of this material through sol-gel and solidstate methods, respectively, and conclusively demonstrate that its crystallography is a direct consequence of the synthetic route and not an inherent property of the composition, as previously argued. This was accomplished via complementary techniques that probe the bulk and local structure followed by in situ methods to map the synthetic progression. As the electrochemical performance and anionic redox behaviour is often rationalised on the basis of the presumed crystal structure, clarifying the structural ambiguities is an important step towards harnessing its potential as an electrode material.
\end{abstract}




\section{Introduction}

The search for novel high energy density positive electrode materials for $\mathrm{Li}$-ion batteries have led to the discovery of several promising but increasingly complex materials, such as the Li- and $\mathrm{Mn}$-rich layered transition metal oxide system. ${ }^{1}$ In particular, $\mathrm{Li}_{1.2} \mathrm{Mn}_{0.54} \mathrm{Ni}_{0.13} \mathrm{Co}_{0.13} \mathrm{O}_{2}(\mathrm{LMNCO})$, is considered a likely candidate for commercialisation due to its high specific capacity $(\sim 300 \mathrm{mAh} / \mathrm{g})$, facilitated by the joint participation of cations and anions in its functional redox process. ${ }^{2}$ However, harnessing the high capacity comes at the cost of irreversible capacity loss and voltage hysteresis over continued electrochemical cycling originating from structural transformations in the material. ${ }^{2,3}$ Among other approaches, crystallographic modifications have been successful in improving the electrochemical performance of LMNCO, although much work remains to be done. ${ }^{4-6}$

Efforts aimed at further developing the LMNCO system must be complemented by fundamental investigations of physical characteristics and properties. This is especially relevant due to the chemical and structural complexity of LMNCO, where gaps in our knowledge of the crystallographic structure exist. LMNCO is argued to exist in multiple crystallographic forms (Fig. 1a) - as a single-phase (SP) solid solution, expressed as $\mathrm{Li}\left[\mathrm{Li}_{0.2} \mathrm{Mn}_{0.54} \mathrm{Ni}_{0.13} \mathrm{Co}_{0.13}\right] \mathrm{O}_{2}{ }^{7,8}$ and as a multi-phase (MP) material, existing as an inter-growth of cation-ordered monoclinic $\mathrm{Li}_{2} \mathrm{MnO}_{3}{ }^{9}$ and transition metal (TM)-disordered hexagonal $\mathrm{LiNi}_{0.33} \mathrm{Mn}_{0.33} \mathrm{Co}_{0.33} \mathrm{O}_{2}{ }^{10}$ phases $\left(x\left[\mathrm{Li}_{2} \mathrm{MnO}_{3}\right] \cdot 1-x\left[\mathrm{LiTMO}_{2}\right], x=0.5\right){ }^{11-13}$ These phases are said to exist as domains integrated through a shared cubic close packed (ccp) $\mathrm{O}^{2-}$ substructure. Although both models possess long-range Li-TM superstructure ordering, the manifestation of this ordering in the TM layers differs. In the single-phase model, superstructure arises from preferential occupation of $2 \mathrm{~b}$ and $4 \mathrm{~g}(\mathrm{C} 2 \mathrm{~m})$ crystallographic sites by Li and Mn, respectively; with Co and Ni distributed across the two sites. ${ }^{14}$ In the multi-phase model, the superstructure is formed by $\mathrm{Li}$ and $\mathrm{Mn}$ ordering within the $\mathrm{Li}_{2} \mathrm{MnO}_{3}$ phase/domain, where $\mathrm{Li}$ in the TM layer is surrounded exclusively by $\mathrm{Mn}^{11,13}$ However, these models are idealized disorder-free representations and in reality, structural disorder occurs leading to variation from the ideal case. $^{7,14}$

Structural characterization of LMNCO is complicated by three kinds of disorders that manifest across different crystallographic length scales; (1) Li-TM site mixing (in the TM layer), (2) stacking faults and (3) inter-layer $\mathrm{Li}^{+}-\mathrm{Ni}^{2+}$ mixing. These are schematically illustrated in Fig. $1 \mathrm{~b}$ and have been reported in several works, irrespective of the structure model employed. ${ }^{7,8,11,12}$ Fig. 1c shows the X-ray diffraction patterns of LR-TMOs, with that of $\mathrm{LiNi}_{0.33} \mathrm{Mn}_{0.33} \mathrm{Co}_{0.33} \mathrm{O}_{2}$. The underlying similarity between these compounds, due to their layered structure is apparent. The primary difference between the patterns are the superstructure reflections in the $20^{\circ}-35^{\circ} 2 \theta_{\mathrm{Cu}-\mathrm{K} \alpha}$ range (1.4-2.4 $\AA^{-1}$ in Q-space) in the Li-rich systems. The diffraction pattern of $\mathrm{LiNi}_{0.33} \mathrm{Mn}_{0.33} \mathrm{Co}_{0.33} \mathrm{O}_{2}$ on the other hand, does not possess superstructure reflections due to the random distribution of TM ions in the TM layer. ${ }^{10}$ The asymmetric broadening of the superstructure reflections (Warren fall ${ }^{15}$ ) in the Li-rich materials originate from the disruption of periodicity in the $c$ direction due to TM layer stacking faults. ${ }^{8,16}$ This disruption can manifest in multiple ways in LMNCO. For example, in the MP model, stacking faults may be caused when $\mathrm{Li}_{2} \mathrm{MnO}_{3}$-like ( $\mathrm{Li}-\mathrm{Mn}$ ) stacking is interrupted by a $\mathrm{LiNi}_{0.33} \mathrm{Mn}_{0.33} \mathrm{Co}_{0.33} \mathrm{O}_{2}$-like TM-only layer, in addition to irregular stacking of similar layertypes. 


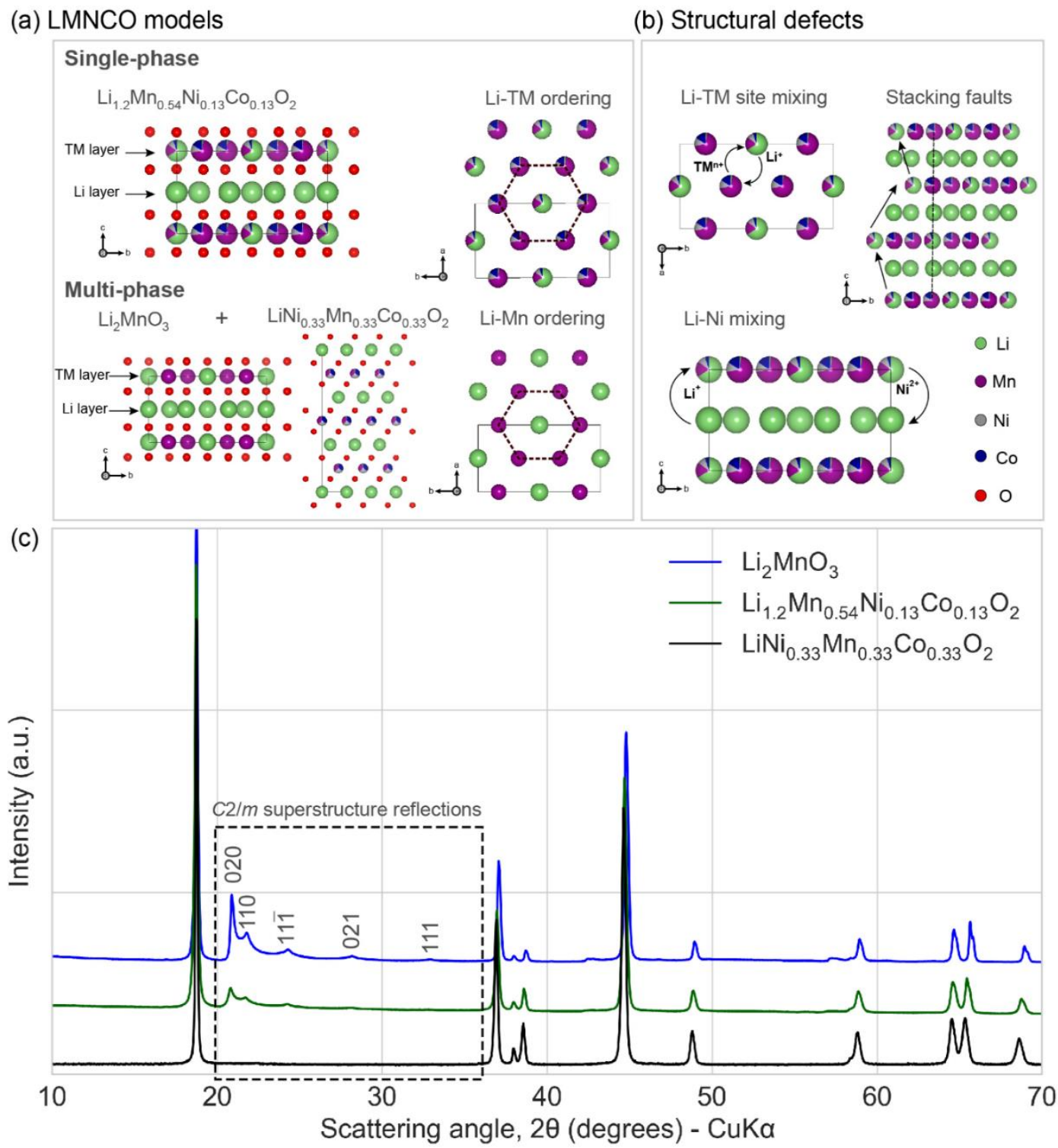

Figure 1: (a) Single- and multi-phase LMNCO structure models. The Li-transition metal (TM) and Li-Mn ordering in the corresponding models are also shown. Dashed hexagons represent superstructures. (b) Structural defects that can occur in Li- and Mn-rich layered transition metal oxides. (c) Stacked normalised X-ray diffraction patterns of $\mathrm{Li}_{2} \mathrm{MnO}_{3}, \mathrm{Li}_{1.2} \mathrm{Mn}_{0.54} \mathrm{Ni}_{0.13} \mathrm{Co}_{0.13} \mathrm{O}_{2}$ and $\mathrm{LiNi}_{0.33} \mathrm{Mn}_{0.33} \mathrm{Co}_{0.33} \mathrm{O}_{2}$. The superstructure reflections in $\mathrm{Li}_{2} \mathrm{MnO}_{3}$ and $\mathrm{Li}_{1.2} \mathrm{Mn}_{0.54} \mathrm{Ni}_{0.13} \mathrm{Co}_{0.13} \mathrm{O}_{2}$ are indexed with $C 2 / m$ space group symmetry.

The determination of LMNCO as single- or multi-phase is non-trivial as the synthesis method has a thermodynamic influence on the material structure. Shukla et al. have shown that the bulk structure of LMNCO is composed of monoclinic phases with randomly stacked domains. ${ }^{7}$ However, the existence of separate $\mathrm{Li}_{2} \mathrm{MnO}_{3}$ and $\mathrm{Li}-\mathrm{TM}-\mathrm{O}_{2}$ domains/phases in $\mathrm{LMNCO}$ have also been reported by $\mathrm{Yu}$ et al. among others. ${ }^{11,13}$ In addition to slight stoichiometric variations, these studies employ different material synthesis protocols. It is also worth noting that, although the effects of parameters such as sintering temperature and synthesis route on the properties of LMNCO have been investigated, ${ }^{17-19}$ a specific structural model was assumed for the analysis. However, due to the compositional and crystallographic complexity of LMNCO, it is reasonable to assume that synthetic variations can lead to dissimilar non-equilibrium crystallographic 
structures, resulting in the aforementioned contradictory observations. ${ }^{20}$ Considering that a thermodynamically stable product is not reached (due to limited heat treatment), a single structure model is often insufficient to describe this system.

The present work investigates the hypothesis that the LMNCO synthetic pathway defines the observed crystal structure. Towards this, LMNCO was intentionally synthesised via two approaches with extremely contrasting degrees of precursor mixing, solid-state and sol-gel, with the intent that each would produce significant crystallographic and morphological differences. The products were characterised over different structural length scales using X-ray and neutron powder diffraction, Raman spectroscopy, electron microscopy, and magnetic measurements, thus providing a complete structural perspective beyond the 'single vs. multi-phase' debate surrounding this material. The observed differences were rationalized through investigation of the synthesis process in situ through thermal and powder diffraction analysis and synthesis-structure relationships are established. 


\section{Methods}

\section{Synthesis}

$\mathrm{Li}_{1.2} \mathrm{Mn}_{0.54} \mathrm{Ni}_{0.13} \mathrm{Co}_{0.13} \mathrm{O}_{2}$ (LMNCO) samples were synthesized using solid-state and sol-gel methods. For solid-state synthesis, the precursors - lithium carbonate $\left({ }^{7} \mathrm{Li}_{2} \mathrm{CO}_{3}\right.$, Sigma-Aldrich, $\left.99 \%{ }^{7} \mathrm{Li}\right)$, manganese (IV) dioxide $\left(\mathrm{MnO}_{2}\right.$, Alfa Aesar, 98\%), nickel (II) oxide (NiO, Alfa Aesar, 99\%) and cobalt (II, III) oxide $\left(\mathrm{Co}_{3} \mathrm{O}_{4}\right.$ Alfa Aesar, 99.7\%) were thoroughly mixed using mortar and pestle. ${ }^{7} \mathrm{Li}_{2} \mathrm{CO}_{3}$ was used to reduce neutron absorption by ${ }^{6} \mathrm{Li}$ in natural $\mathrm{Li}$. A $\sim 10 \mathrm{wt}$.\% excess of $\mathrm{Li}_{2} \mathrm{CO}_{3}$ was used to compensate for the loss of $\mathrm{Li}$ during high temperature annealing.

The sol-gel precursor was prepared through a modified Pechini sol-gel based method. ${ }^{21}$ Stoichiometric amounts of lithium acetate dihydrate $\left(\mathrm{CH}_{3} \mathrm{COOLi} \cdot 2 \mathrm{H}_{2} \mathrm{O}\right.$, Sigma-Aldrich, reagent grade), manganese (II) acetate tetrahydrate $\left(\left(\mathrm{CH}_{3} \mathrm{COO}\right)_{2} \mathrm{Mn} \cdot 4 \mathrm{H}_{2} \mathrm{O}\right.$, Sigma-Aldrich, $\left.\geq 99 \%\right)$, nickel(II) acetate tetrahydrate $\left(\left(\mathrm{CH}_{3} \mathrm{COO}\right)_{2} \mathrm{Ni} \cdot 4 \mathrm{H}_{2} \mathrm{O}\right)$, Sigma-Aldrich, $\left.\geq 99 \%\right)$, and cobalt(II) acetate tetrahydrate $\left(\left(\mathrm{CH}_{3} \mathrm{COO}\right)_{2} \mathrm{Co} \cdot 4 \mathrm{H}_{2} \mathrm{O}\right.$, Sigma-Aldrich, $\geq 99 \%$ ) were dissolved in $300 \mathrm{~mL}$ of deionized water. An excess of the Li source, approximately $2.5 \%$ by weight was again used to account for Li loss during annealing. Similarly, a $300 \mathrm{~mL}$ aqueous solution of citric acid (Sigma-Aldrich, $\geq 99.5 \%$ ) and EDTA (ethylenediaminetetraacetic acid, ACS reagent) was also prepared. The cation : citric acid : EDTA molar ratio was approximately $1: 1.5: 1$. The two solutions were thoroughly mixed by magnetic stirring for $1 \mathrm{~h}$ after which, the $\mathrm{pH}$ was adjusted to approximately 7.5 using ammonium hydroxide solution $\left(\mathrm{NH}_{4} \mathrm{OH}\right.$, Sigma-Aldrich, 28-30\%). The solution was heated at $120{ }^{\circ} \mathrm{C}$ overnight while stirring, which led to the formation of a dry gel that was then crushed into a powder. This powder was then transferred to an alumina crucible and heated in a muffle furnace in air at $500{ }^{\circ} \mathrm{C}\left(5^{\circ} \mathrm{C} / \mathrm{min}\right.$ ramp) for $5 \mathrm{~h}$, and allowed to cool to room temperature in the furnace.

The two precursors (mixture of powder precursors for the solid-state method and the pre-heated precursor for the sol-gel method) were separately transferred to an alumina crucible and annealed in air at $900{ }^{\circ} \mathrm{C}(5$ ${ }^{\circ} \mathrm{C} / \mathrm{min}$ ramp) for $12 \mathrm{~h}$ using a muffle furnace. After annealing, they were quenched to room temperature by bringing the crucibles in contact with an aluminium plate.

Two additional samples, $\mathrm{Li}_{2} \mathrm{MnO}_{3}$ and $\mathrm{LiNi}_{0.33} \mathrm{Mn}_{0.33} \mathrm{Co}_{0.33} \mathrm{O}_{2}$, were also studied for comparative purposes. $\mathrm{Li}_{2} \mathrm{MnO}_{3}$ was synthesized in a similar way to sol-gel $\mathrm{LMNCO}$, whereas $\mathrm{LiNi}_{0.33} \mathrm{Mn}_{0.33} \mathrm{Co}_{0.33} \mathrm{O}_{2}$ was obtained commercially from Custom Cells Itzehoe $\mathrm{GmbH}$.

\section{Characterization}

Elemental analysis was carried out by inductively coupled plasma - optical emission spectroscopy (ICPOES) measurements with a Perkin Elmer ICP-OES Avio 200 system. The powders were dissolved in a $\mathrm{HCl}$ $: \mathrm{HNO}_{3}(3: 1 \mathrm{v} / \mathrm{v})$ solution (ICP grade) and diluted to the required concentration using a solution of $5 \mathrm{vol} . \%$ $\mathrm{HNO}_{3}$ in ultra-pure Milli-Q water (blank) prior to the analysis. The Perkin Elmer Pure Plus Multi-element calibration standard was used as the reference for the ICP-OES measurements.

The particle size and morphology were studied using a Zeiss LEO 1550 scanning electron microscope (SEM). The powdered samples were spread on carbon tape and coated with a thin layer of AuPd alloy to prevent charging. The images were obtained at an accelerating voltage of $5 \mathrm{kV}$ using the InLens detector. Powder samples for transmission electron microscopy were prepared by crushing the powder in a mortar followed by sonication in anhydrous ethanol and drop casting the dispersion on a holey-carbon copper grid. 
Scanning transmission electron microscopy and X-ray energy-dispersive spectroscopy (STEM-EDX) maps were recorded using a probe corrected FEI Titan Themis 200 microscope operating at $200 \mathrm{kV}$ equipped with a four-detector Super-X EDS system. The EDS images were acquired and evaluated with the software ESPRIT 1.9 from Bruker. Quantification was performed standard-less with the Cliff-Lorimer method using theoretical k-factors provided by the software.

Thermogravimetric and differential thermal analysis (TG-DTA) were performed simultaneously using a Netzsch STA 409 thermal analyser. The precursor mixture was placed in an alumina crucible and heated at $5{ }^{\circ} \mathrm{C} / \mathrm{min}$ from 25 to $900{ }^{\circ} \mathrm{C}$ in air $(60 \mathrm{~mL} / \mathrm{min}$ flow rate).

Synchrotron X-ray diffraction (XRD) experiments were performed on the Powder Diffraction beamline ${ }^{22}$ at the Australian Synchrotron. The powder samples were packed in $0.5 \mathrm{~mm}$ (diameter) quartz capillaries and data collected in transmission mode using the Mythen II detector from $1-81^{\circ}(2 \theta)$ using a wavelength of $0.7736831(8) \AA(\sim 16 \mathrm{keV})$. Two data sets were collected for $40 \mathrm{~s}$ each with the detector set $0.5^{\circ}$ apart to cover gaps between the detector modules; these were then merged using the in-house software, PDViPeR. The wavelength and instrumental parameters were determined using data collected for the NIST $660 \mathrm{~b} \mathrm{LaB} 6$ standard reference material. Constant wavelength neutron powder diffraction (NPD) data were collected on the high-resolution neutron powder diffractometer, Echidna ${ }^{23}$ at the Australian Nuclear Science and Technology Organisation (ANSTO). The solid-state and sol-gel samples were measured using neutron wavelengths of 1.62183(2) and 1.62189(2) $\AA$, respectively. For the measurement, $\sim 2.1 \mathrm{~g}$ of the solid-state sample and $\sim 0.378 \mathrm{~g}$ of the sol-gel sample was packed into six and nine $\mathrm{mm}$ (diameter) vanadium cans, respectively. Data were collected over a $2 \theta$ range of $5^{\circ}-164^{\circ}$ for a duration of $4 \mathrm{~h}$ for the solid-state sample and $10 \mathrm{~h}$ for the sol-gel sample. The wavelength and the instrumental parameters were determined using the NIST $660 \mathrm{~b} \mathrm{La}{ }^{11} \mathrm{~B}_{6}$ standard reference material.

In situ synchrotron XRD measurements were performed at the I11 High Resolution Powder Diffraction beamline $^{24}$ at the Diamond Light Source with a wavelength of 0.8265203(3) $\AA$. The precursor mixture was loaded into a $0.5 \mathrm{~mm}$ (diameter) quartz capillary and heated using a Cyberstar hot-air blower. The capillary, under rotation, was initially heated to $400{ }^{\circ} \mathrm{C}$ at $\sim 12{ }^{\circ} \mathrm{C} / \mathrm{min}$, and then at $\sim 6^{\circ} \mathrm{C} / \mathrm{min}$ until the end. Diffraction data were collected with an acquisition time of $20 \mathrm{~s}$ throughout the heating using the Mythen position sensitive detector. Data collection was stopped at $\sim 800{ }^{\circ} \mathrm{C}$ due to reaction between the sample and capillary. The wavelength and instrumental parameters were determined using data for the NIST 640c Si standard reference material. In situ NPD experiments were performed at the high-intensity neutron powder diffractometer, Wombat, ${ }^{25}$ at ANSTO over a $2 \theta$ range $\left(16-136^{\circ}\right)$. The solid-state and sol-gel samples were measured using neutron wavelengths of 2.41656(7) and 2.41580(7) A, respectively. The precursors were packed in cylindrical Pt cans, which were then heated in a high-temperature furnace (ILL type, niobium element vacuum furnace) equipped with a Pt tube insert. The solid-state sample was heated from room temperature to $300{ }^{\circ} \mathrm{C}$ at $10{ }^{\circ} \mathrm{C} / \mathrm{min}$, while the sol-gel sample was heated to the same temperature at 5 ${ }^{\circ} \mathrm{C} / \mathrm{min}$. They were then heated to $900{ }^{\circ} \mathrm{C}$ at $5{ }^{\circ} \mathrm{C} / \mathrm{min}$ and annealed for $6 \mathrm{~h}$ after which, the furnace was allowed to cool. Diffraction data were recorded every minute during the thermal treatment. The wavelength and the instrumental parameters were determined using the data for the NIST $660 \mathrm{~b} \mathrm{La}^{11} \mathrm{~B}_{6}$ standard reference material.

Instrumental parameters of the diffractometers were determined by Pawley refinement ${ }^{26}$ of the corresponding unit cells against data collected from the standard reference materials. Refinement of the hexagonal $(R \overline{3} m)$ and monoclinic $(C 2 / m)$ unit cell parameters of the samples against X-ray diffraction data 
was performed using TOPAS Academic (V6) software. ${ }^{27}$ The monoclinic cell is a supercell of the hexagonal cell and they are related using the equation shown below, where $\bar{a}, \bar{b}$ and $\bar{c}$ are the unit cell parameters.

$$
\left(\begin{array}{lll}
\bar{a} & \bar{b} & \bar{c}
\end{array}\right)_{C 2 / m}=\left(\begin{array}{ccc}
\bar{a} & \bar{b} & \bar{c}
\end{array}\right)_{R \overline{3} m} \cdot\left(\begin{array}{ccc}
-2 & 0 & 2 / 3 \\
-1 & -3 & 1 / 3 \\
0 & 0 & 1 / 3
\end{array}\right)
$$

Refinement (Rietveld ${ }^{28,29}$ ) of the LMNCO structures against X-ray and neutron diffraction data were carried out with FAULTS ${ }^{30}$ and TOPAS, respectively. FAULTS facilitates the refinement of stacking faulted structures, thereby enabling an investigation of the degree of faulting within the structure in addition to other structural parameters. The single-phase stacking-faulted LMNCO structure model was obtained by adapting a previously reported $\mathrm{Li}_{2} \mathrm{MnO}_{3}$ structure ${ }^{31}$ to the $\mathrm{LMNCO}$ structure and approximating the TM species to Mn (i.e., $\mathrm{Li}_{1.2} \mathrm{Mn}_{0.54} \mathrm{Ni}_{0.13} \mathrm{Co}_{0.13} \mathrm{O}_{2}=\mathrm{Li}_{1.2} \mathrm{Mn}_{0.8} \mathrm{O}_{2}$ ), to avoid over-parameterization. The difference between the TM electronic charges before and after this approximation is $\sim 5.8 \%$ and therefore, is reasonable. For SS-LMNCO, a two-phase model comprising of stacking-faulted $\mathrm{Li}_{2} \mathrm{MnO}_{3}{ }^{31}$ and $\mathrm{LiNi}_{0.33} \mathrm{Mn}_{0.33} \mathrm{Co}_{0.33} \mathrm{O}_{2}{ }^{10}$ phases was used, with the latter being incorporated as a background phase. Refinements against neutron diffraction data was carried out without using stacking faulted structure models. The single-phase structure model was obtained by modifying the LMNCO structure model reported by Whitfield et al. ${ }^{14}$ to fit the stoichiometry of the LMNCO samples in this study. Multi-phase LMNCO structure refinements were performed using $\mathrm{Li}_{2} \mathrm{MnO}_{3}{ }^{9}$ and $\mathrm{LiNi}_{0.33} \mathrm{Mn}_{0.33} \mathrm{Co}_{0.33} \mathrm{O}_{2}{ }^{10}$ structures, similar to conventional multi-phase Rietveld refinements. Additional details of the refinement procedures and the refined values are provided in the Supplementary Information sections S6 and S7. Crystallographic structures were visualized using the VESTA software. ${ }^{32}$ It should be noted that diffraction data have been plotted in terms of the reciprocal space scattering vector, $\mathrm{Q}\left(\AA^{-1}\right)$ to facilitate direct comparison between the different datasets. $\mathrm{Q}$ is related to the scattering angle $(2 \theta)$ by, $Q=(4 \cdot \pi \cdot \sin \theta) / \lambda$, where $\lambda$ is the wavelength of incident radiation.

The magnetic properties were measured with a Quantum Design magnetic property measurement system (MPMS-XL). The temperature dependence of constant field DC magnetization was measured from 300 to $2 \mathrm{~K}$. Each sample was first cooled to $2 \mathrm{~K}$ in zero field, then a field of $100 \mathrm{Oe}$ was applied and data collected between 2 and $300 \mathrm{~K}$ (zero-field-cooling mode, ZFC). The sample was then cooled under the same applied field from 300 to $2 \mathrm{~K}$, while magnetization was measured (field-cooling mode, FC). Isothermal magnetization curves were measured at $5 \mathrm{~K}$ in magnetic fields up to $\pm 50000 \mathrm{Oe}$. The temperature dependent sinusoidally varied (AC) susceptibility $\chi=\chi^{\prime}+i \chi^{\prime \prime}$, where $\chi^{\prime}$ is the in-phase component and $\chi^{\prime \prime}$, the out-ofphase component of the AC susceptibility, was measured in an AC magnetic field of 4 Oe at various frequencies $(1.7,17,170 \mathrm{~Hz})$ within the temperature range, 250 to $2 \mathrm{~K}$. The inverse magnetic susceptibility curves were fitted to the Curie-Weiss law $(\chi=C /(T-\theta)$, where $\mathrm{C}$ is the Curie constant, $\mathrm{T}$ is the temperature, and $\theta$ is the Curie-Weiss temperature) by the $\mathrm{SciPy}^{33}$ 'curve_fit' optimization function.

Raman spectra were measured on a Renishaw InVia Raman microscope with an excitation wavelength of $532 \mathrm{~nm}$ over the range of 1000 to $100 \mathrm{~cm}^{-1}$. Prior to the measurements, instrument calibration was performed using the internal Si reference standard $\left(520.6 \pm 0.1 \mathrm{~cm}^{-1}\right)$. To improve the data quality, ten spectra with an individual $15 \mathrm{~s}$ exposure time were averaged for each sample.

Galvanostatic cycling was conducted using swagelok cells prepared in an argon-filled glovebox in half-cell configuration. The working electrode was prepared by mixing $\sim 75 \mathrm{wt} . \%$ of the active material (LMNCO) and $\sim 25$ wt. $\%$ of carbon black (Super $\mathrm{P} \circledast$ Conductive, Alfa Aesar, 99\%) using a mortar and pestle. This mixture was dried overnight in a vacuum oven inside the glovebox at $120^{\circ} \mathrm{C}$. Half-cells were prepared using 
Li metal as a counter electrode and two glass fibre separators (dried at $150{ }^{\circ} \mathrm{C}$ for $6 \mathrm{~h}$ in vacuum inside the glovebox), with a standard electrolyte solution of $1 \mathrm{M} \mathrm{LiPF}_{6}$ in ethylene carbonate (EC) : diethyl carbonate (DEC) (1:1 vol.\%) (Sigma aldrich, 99\%). The cells were cycled on the Land BT2000 battery testing system between 2.0 to $4.8 \mathrm{~V}$ at $5 \mathrm{~mA} / \mathrm{g}$ under ambient conditions $\left(\sim 22{ }^{\circ} \mathrm{C}\right)$, with an initial resting step at the open circuit voltage $(\mathrm{OCV})$ for $5 \mathrm{~h}$. 


\section{$\underline{\text { Results and discussion }}$}

\section{Morphology, stoichiometry and long-range crystallographic structure}

(a)

(c)
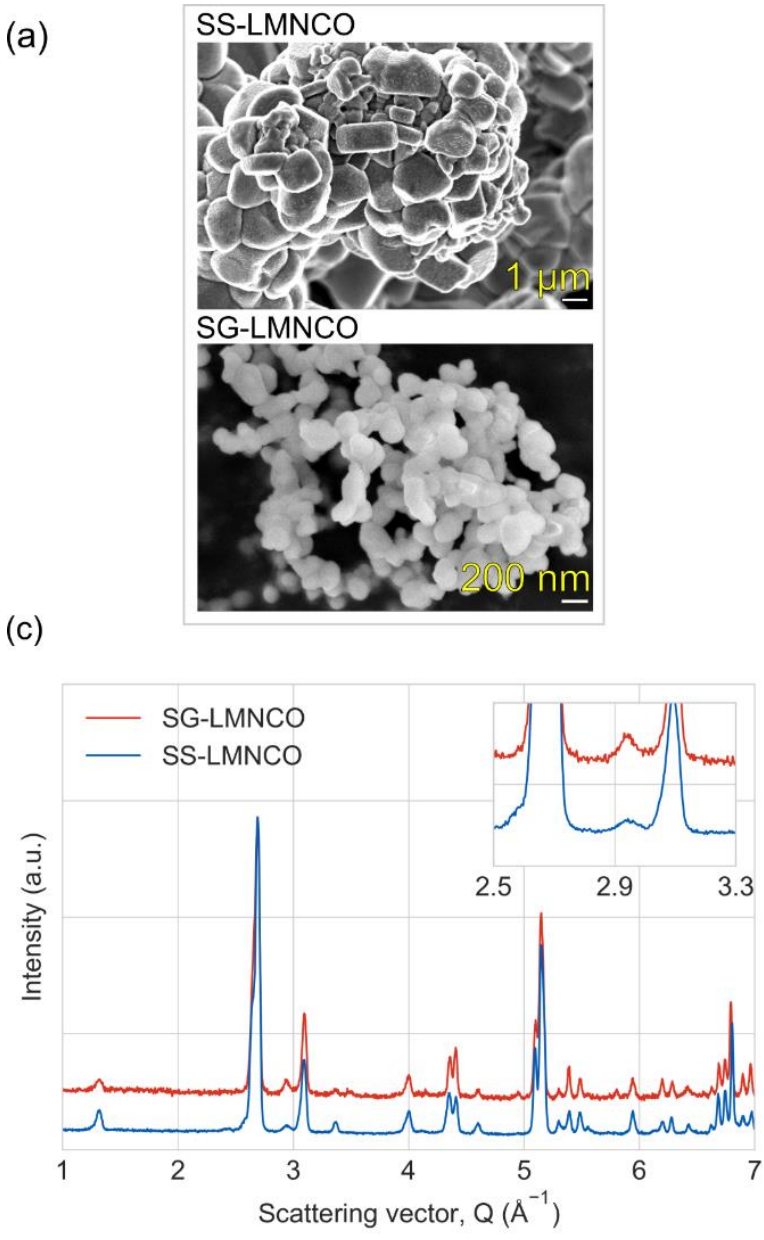

(b)

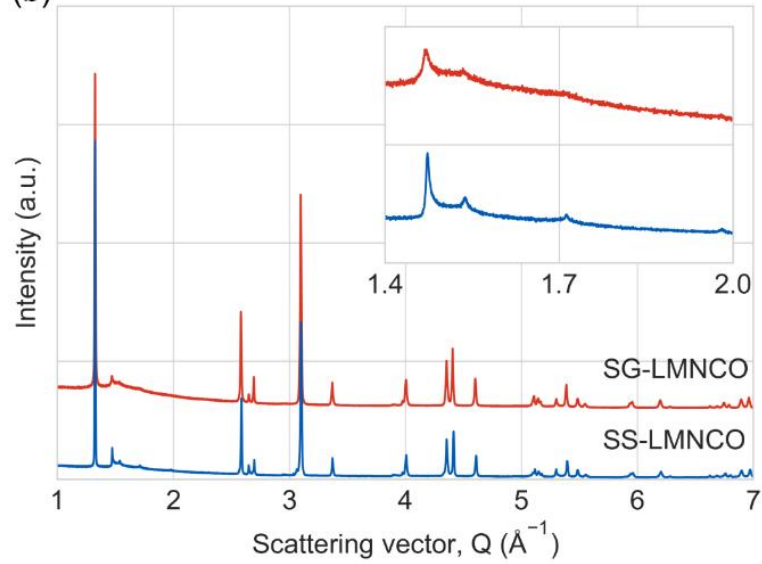

(d)

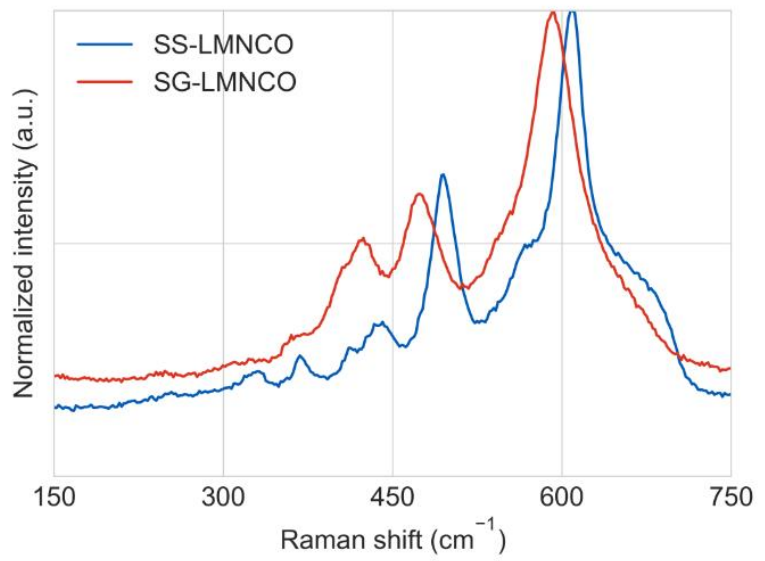

Figure 2: (a) SEM images (scale bars represent $1 \mu \mathrm{m}$ and $200 \mathrm{~nm}$ for SS-LMNCO and SG-LMNCO, respectively), stack plots of (b) X-ray and (c) neutron diffraction patterns of the LMNCO samples (intensities are normalised to highest values) along with their (d) Raman spectra. The inset in (b) and (c) shows a Q-space region with superstructure reflections.

The as-synthesized samples noticeably differed in their morphology (Fig. 2a). The solid-state LMNCO sample (SS-LMNCO) had heterogeneous secondary particles several micrometres in size formed from tightly packed primary particles of varying sizes, with particles at the surface $(\sim 1-3 \mu \mathrm{m})$ larger than interior ones $(\sim 0.5-1 \mu \mathrm{m})$. The sol-gel sample (SG-LMNCO) was predominantly composed of loosely bound homogeneously shaped particles, $100-200 \mathrm{~nm}$ in size. The Li:Mn:Ni:Co stoichiometry of the samples was determined by inductively coupled plasma optical emission spectroscopy (ICP-OES) analysis to be 1.216(13):0.533(19):0.125(9):0.12(1) and 1.2101(33):0.536(16):0.128(34):0.124(31) for SS-LMNCO and SG-LMNCO, respectively (Supplementary Table S1). The two compositions are therefore comparable, with a Li content slightly higher than expected due to the excess used in synthesis. The diffraction data in Fig. 2 reveal an overall structural similarity between the samples, with the exception of the superstructure reflections (inset in Figs. $2 \mathrm{~b}$ and $2 \mathrm{c}$ ). The parent hexagonal $(R \overline{3} m)$ unit cell of the two materials were 
compared using Pawley ${ }^{26}$ analysis of the X-ray diffraction (XRD) data. The unit cell parameters of the samples show slight differences; $0.16 \%$ and $0.04 \%$ for $a(b)$ and $c$ lattice parameters, respectively, and are tabulated in the Supplementary Table S2. The $c / 3 a$ value, a measure of the deviation of the hexagonal lattice from the ideal cubic close packed (ccp) arrangement ( $c / 3 a=1.633$ ), is comparable (difference of $\sim 0.2 \%$ ) between the samples and to other layered $\mathrm{LiNi}_{x} \mathrm{Mn}_{y} \mathrm{Co}_{1-x-y} \mathrm{O}_{2}$ systems, ${ }^{34}$ signifying that the samples have a well-crystallised layered structure. However, the presence of superstructure reflections and the different peak amplitude of the 108 and 110 reflections $\left(R \overline{3} m\right.$ symmetry, observable at $\sim 4.5 \AA^{-1}$ ), unambiguously evidence a monoclinic symmetry. Pawley refinement of a monoclinic $(C 2 / m)$ unit cell are tabulated in the Supplementary Table S3. Despite the close composition and bulk crystallographic structure of the two samples, the differences in Raman spectra of the samples (Fig. 2d) are quite distinct. However, as the deconvolution of the spectra is complicated by the elemental composition, structural disorder, and microstructural differences, conclusions that can be drawn from it are limited. A qualitative analysis of the spectra, presented in the Supplementary Information (SI) section 3, points towards incomparable local TMO coordination environments in the samples, with the SS-LMNCO sample suggesting the possible existence of multiple phases. Taken together, these results establish that the two LMNCO samples have comparable stoichiometry and long-range average structure, but dissimilar local structural features.

\section{Differences in local TM distribution}

(a)

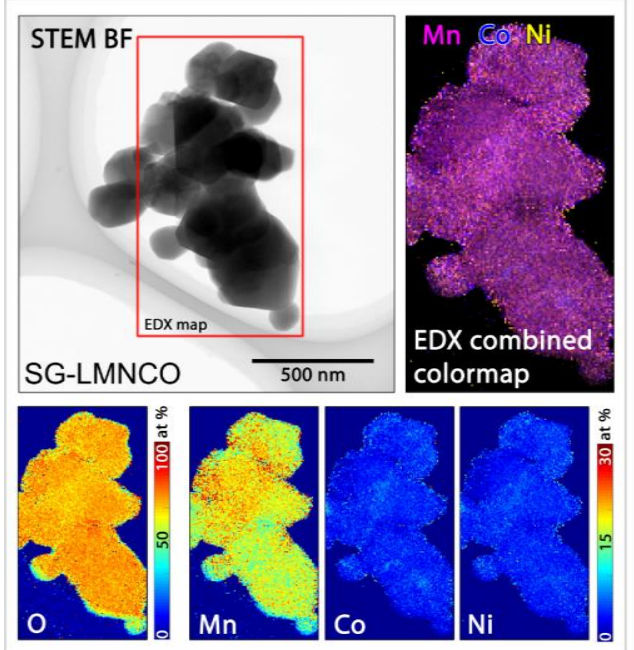

(b)

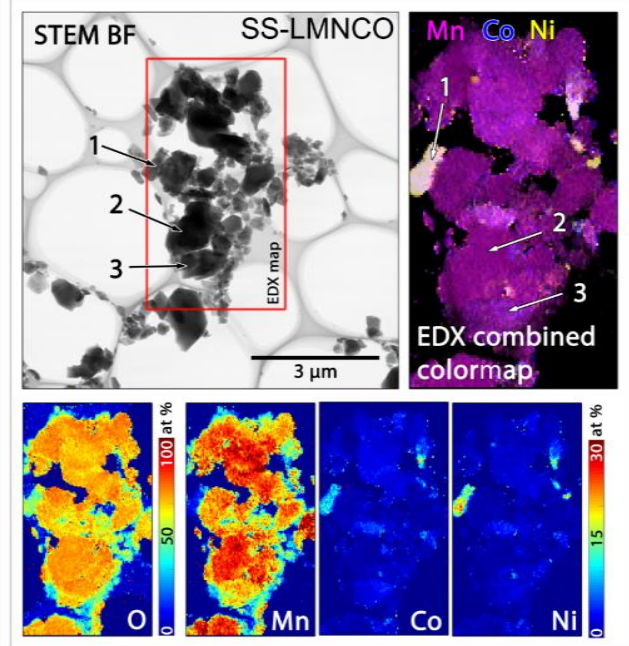

Figure 3: Bright field (BF) STEM data with EDX maps of (a) SG-LMNCO and (b) SS-LMNCO. Quantified elemental maps are shown at the bottom.

As the two LMNCO models have identical average structures, characterization techniques sensitive to the local (Li-)TM ordering, must be employed to investigate the structural differences. Here, the TM distributions of the samples were probed at different length scales using scanning transmission electron microscopy X-ray energy dispersive spectroscopy (STEM-EDX) and magnetic measurements. EDX mapping was carried out at microscopic length scales to probe the chemical homogeneity of the samples. The SG-LMNCO map revealed a homogeneous distribution of TMs without microscopic segregation of any species, including oxygen which was uniformly distributed and close to the expected $\sim 71 \mathrm{~mol} \%$. The quantified values for the constituent elements are comparable to the composition of LMNCO (Supplementary Tables S4 and S5). On the other hand, the SS-LMNCO sample is inhomogeneous and composed of at least three chemically distinct particle types or regions, which are shown in Fig. 3b (and 
highlighted in Supplementary Fig. S4), with the corresponding compositions tabulated in the Supplementary Table S5. Region 1 is predominantly composed of $\mathrm{Ni}$ and $\mathrm{Co}$. The $\mathrm{O}$ content was quantified to be $\sim 62 \%$, which is lower than that of $\mathrm{LiNi}_{0.33} \mathrm{Mn}_{0.33} \mathrm{Co}_{0.33} \mathrm{O}_{2}(66 \%)$. Region 2, almost devoid of $\mathrm{Ni}$ and $\mathrm{Co}$, has $\mathrm{O}$ and Mn contents of $\sim 72.5$ and $\sim 25 \%$, which are comparably close to that of $\mathrm{Li}_{2} \mathrm{MnO}_{3}$. Region 3 has a considerable amount of all species, with the $\mathrm{Mn}$ and $\mathrm{O}$ values conforming to the values expected from LMNCO. However, the $\mathrm{Ni}$ and Co values are lower than expected. This suggests that either the $\mathrm{Li}_{2} \mathrm{MnO}_{3}$ like phase is present in excess and the composition of the Li-Ni-Mn-Co-O phase is manganese deficient or that the $\mathrm{Li}_{2} \mathrm{MnO}_{3}$-like phase is over-represented within the area probed. These results suggest that the sample could be composed of $\mathrm{Li}_{2} \mathrm{MnO}_{3}$ and $\mathrm{Li}\left[\mathrm{Ni}_{y} \mathrm{Co}_{z} \mathrm{Mn}_{1-y-z}\right] \mathrm{O}_{2}(y, z \geq 0.33)$ phases integrated heterogeneously, ranging from atomic-scale intergrowths to segregated $\mathrm{Li}_{2} \mathrm{MnO}_{3}$ and $\mathrm{Li}\left[\mathrm{Ni}_{y} \mathrm{Co}_{z} \mathrm{Mn}_{1-y-z}\right] \mathrm{O}_{2}$ particles. Considering that the ICP-OES results establish the conformity of the overall stoichiometry to the expected value, SS-LMNCO may be represented as $(x) \mathrm{Li}_{2} \mathrm{MnO}_{3} \cdot(1-x) \mathrm{Li}\left[\mathrm{Ni}_{y} \mathrm{Co}_{z} \mathrm{Mn}_{1-y-z}\right] \mathrm{O}_{2}$ where $0.5 \leq x \leq$ 1 and $y, z \geq 0.33$. This agrees well with the Raman spectra, which show the peaks for pure $\mathrm{Li}_{2} \mathrm{MnO}_{3}$ and $\mathrm{LiNi}_{0.33} \mathrm{Mn}_{0.33} \mathrm{Co}_{0.33} \mathrm{O}_{2}$ phases (Supplementary Fig. S3). With the EDX data clearly evidencing different TM distributions in the two samples at a microscopic scale, magnetic measurements were performed to probe the distribution within the bulk.

(a)

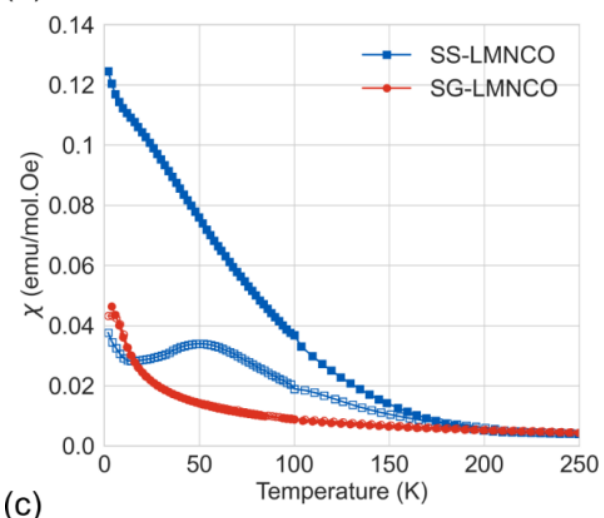

(c)

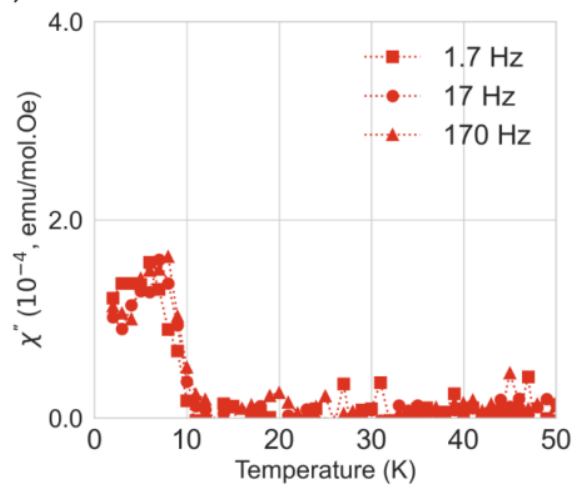

(b)

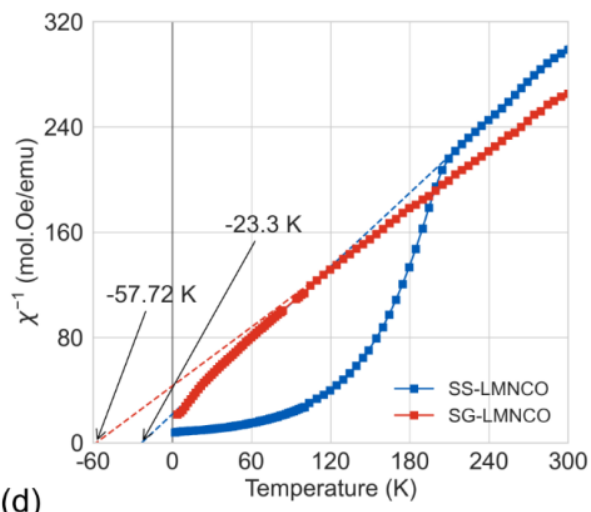

(d)

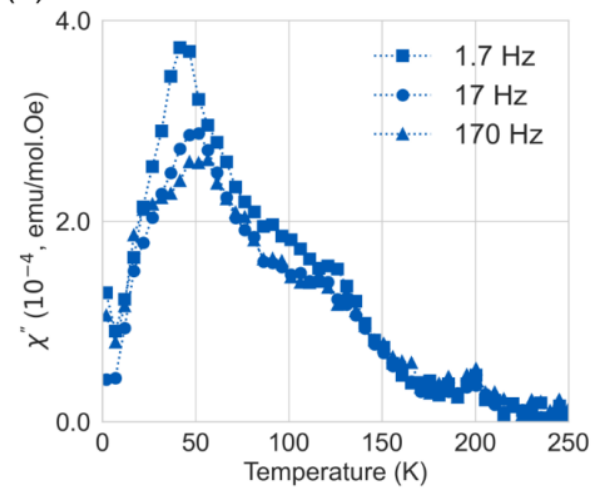

Figure 4: (a) Temperature dependent constant field (DC) magnetic susceptibility $(\chi)$ of the samples. Field cooled (FC) and zero field cooled (ZFC) susceptibilities are shown as filled and empty symbols, respectively. (b) Reciprocal FC susceptibilities with their fits (dashed lines) to the Curie-Weiss law. Temperature dependences of the imaginary/out-of-phase magnetic susceptibility $\left(\chi^{\prime \prime}\right)$ of SG-LMNCO (c) and SS-LMNCO (d). Points are connected by lines for clarity.

The temperature dependent DC magnetic susceptibilities $(\chi)$ of the LMNCO samples show pronounced differences, as seen in Fig. 4a. In SG-LMNCO, the ZFC and FC curves trace the same path until $\sim 8 \mathrm{~K}$, 
where the plots diverge and a cusp is visible in the ZFC susceptibility (Supplementary Fig. S5). This is typical of spin glass systems that are in a state of quenched magnetic disorder due to the presence of randomly oriented magnetic moments. ${ }^{35,36}$ Comparable behaviour is observed in $\mathrm{LiNi}_{0.33} \mathrm{Mn}_{0.33} \mathrm{Co}_{0.33} \mathrm{O}_{2}$, where the spin glass behaviour is realized through configurational disorder facilitated by a random distribution of TMs in the TM layer. ${ }^{36}$ This reasoning may be extended to explain the magnetic response of SG-LMNCO, where a structural configuration with random distribution of TM ions (w.r.t. Li) precludes the formation of magnetic ordering within the sample above $2 \mathrm{~K}$. The layered (rock salt) structure with its stacking of two-dimensional triangular edge sharing planes impart the geometric frustration necessary to realise a spin glass state. An empirical criterion for the realization of a spin glass with magnetic frustration is that the $|\theta| / T_{\mathrm{f}}$ value should be greater than 10 , where $\theta$ is the Curie-Weiss temperature. ${ }^{35}$ As shown in Fig. $4 \mathrm{~b}$, the Curie-Weiss temperature for SG-LMNCO is $-57.72 \mathrm{~K}$, which results in $|\theta| / \mathrm{T}_{\mathrm{f}}$ of 7.21 , suggesting that SG-LMNCO, although not a perfect spin glass system, is close to a state of configurational disorder with respect to the TMs. The out-of-phase ( $\left.\chi^{\prime \prime}\right)$ component of the AC magnetic susceptibility of SG-LMNCO shows a frequency dependent sharp onset of dissipation at $\sim 8 \mathrm{~K}$ (Fig. $4 \mathrm{c}$ ). This onset is found to shift towards lower temperature with lower frequency, as typical of spin glass systems, and further evidencing the absence of magnetic/cation clustering in this sample. Therefore, the magnetic response of SG-LMNCO, in corroboration with the EDX results, does not provide evidence for any TM segregation in the structure. This conclusively rules out the existence of $\mathrm{Li}_{2} \mathrm{MnO}_{3}$ domains in the structure and suggests that SG-LMNCO is similar to the single-phase LMNCO model.

The magnetic response of SS-LMNCO is more complex. The FC and ZFC curves diverge at $200 \mathrm{~K}$, and on further cooling, the FC curve increases strongly while the ZFC curve increases only slowly, displaying an antiferromagnetic like transition at $\sim 50 \mathrm{~K}$. This divergent behaviour of the ZFC-FC curves is characteristic of cluster glass systems composed of phase separated magnetic domains, ${ }^{37,}{ }^{38}$ suggesting that SS-LMNCO is a multi-phase system. The presence of $\mathrm{Li}_{2} \mathrm{MnO}_{3}$ phase is revealed by the antiferromagnetic transition at $\sim 50 \mathrm{~K}$ in the ZFC curve, which is characteristic of this phase (Supplementary Fig. S6). The significant increase of magnetic susceptibility on continued cooling is due to different types of short-range magnetic ordering, including ferromagnetic ordering with a $180^{\circ} \mathrm{Ni}^{2+}{ }_{\mathrm{Li}}$ layer- $\mathrm{O}-\mathrm{Mn}^{4+} \mathrm{TM}$ layer interaction, which can be introduced by $\mathrm{Ni}^{2+}$ in the $\mathrm{Li}$ layer in $\mathrm{Li}\left[\mathrm{Ni}_{y} \mathrm{Co}_{z} \mathrm{Mn}_{1-y-z}\right] \mathrm{O}_{2} / \mathrm{LiNi}_{0.33} \mathrm{Mn}_{0.33} \mathrm{Co}_{0.33} \mathrm{O}_{2}$ domains. ${ }^{36}$ Based on Goodenough's rules, the antiferromagnetic $\mathrm{Mn}-\mathrm{O}-\mathrm{Li}-\mathrm{O}-\mathrm{Mn}$ superexchange interaction in the $\mathrm{Li}_{2} \mathrm{MnO}_{3}$ domains is considered the dominant mechanism. ${ }^{39}$ Similar observations for the compositionally similar (commercial) $\mathrm{Li}_{1.2} \mathrm{Mn}_{0.55} \mathrm{Ni}_{0.15} \mathrm{Co}_{0.10} \mathrm{O}_{2}$ were reported by Mohanty et al. ${ }^{13}$ including a magnetic transition at $\sim 50 \mathrm{~K}$ in the ZFC curve. The slight hysteresis observed in the M-H curve for SS-LMNCO may be attributed to the increased magnetization, as opposed to SG-LMNCO where no hysteresis is observed (Supplementary Fig. S7). From the inverse susceptibility (FC) plot in Fig. 4b, it is evident that SS-LMNCO follows the Curie-Weiss law until $200 \mathrm{~K}$, below which it begins to deviate due to the onset of magnetic (ferromagnetic and antiferromagnetic) ordering in different domains. In the AC susceptibility curves (Fig. 4d), the broad maxima of the $\chi^{\prime \prime}$ component around $50 \mathrm{~K}$, represents dissipation in the vicinity of the expected phase transition, and further confirms the existence of antiferromagnetic $\mathrm{Li}_{2} \mathrm{MnO}_{3}$ domains in the structure. Additionally, a feature is also observed around $200 \mathrm{~K}$ in the $\chi$ " component, signifying the dissipation of ferromagnetic or ferrimagnetic clusters. The Curie-Weiss fit of the samples and calculation of the effective magnetic moments are provided in the SI (Section S5.1). 


\section{Structural analysis using powder diffraction data}

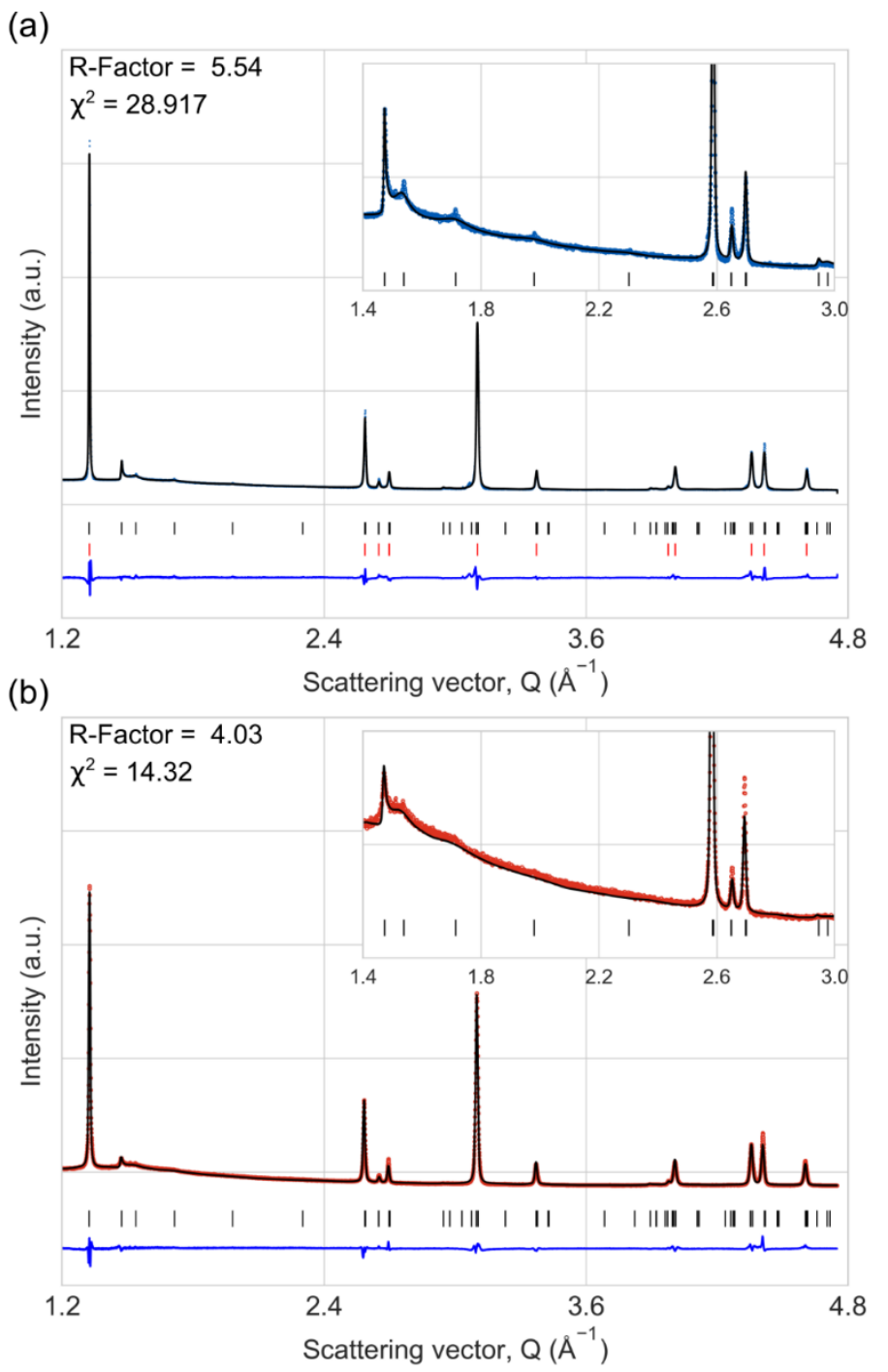

Figure 5: Refinement plots of stacking faulted structure models against XRD data. The observed and calculated intensities are shown as coloured circles and black lines, respectively. The difference curve is shown in blue and the positions of the Bragg reflections as vertical tick markers. In (a) the black and red markers denote $\mathrm{Li}_{2} \mathrm{MnO}_{3}$ and $\mathrm{LiNi}_{0.33} \mathrm{Mn}_{0.33} \mathrm{Co}_{0.33} \mathrm{O}_{2}$ phases, respectively. The definitions of the R-Factor and $\chi^{2}$ can be found in the FAULTS software manual.

The structural differences highlighted by the EDX and magnetic measurements should be visible in diffraction data, the analysis of which can further corroborate the results obtained thus far. Considering the different X-ray and neutron scattering of constituent elements (Supplementary Table. S7) and risk of model over-parameterization, structural refinements against powder diffraction data must be constrained to produce statistically reliable results. Complementary techniques like magnetic measurements are useful in guiding this constraint. Therefore, refinements of stacking-fault incorporated single- and multi-phase LMNCO structure models were carried out against SG-LMNCO and SS-LMNCO XRD data, respectively, using FAULTS. ${ }^{30}$ For SS-LMNCO, refinements were performed using faulted- $\mathrm{Li}_{2} \mathrm{MnO}_{3}$ and 
$\mathrm{LiNi}_{0.33} \mathrm{Mn}_{0.33} \mathrm{Co}_{0.33} \mathrm{O}_{2}$ phases, with the latter incorporated as background. As seen in Fig. 5, satisfactory fits are obtained, and the degree of faulting (explained in Supplementary section S6.2) in SS-LMNCO and SGLMNCO is calculated to be $25.77(10) \%$ and $48.15(20) \%$, respectively. While satisfactory, the fit is less good for SS-LMNCO due to the variation of faulting within the structure as previously reported for LMNCO and other Li-rich layered oxides. ${ }^{7}, 16$ This variation of faulting implies that this material cannot be considered as a 'single-phase', even if in practice a 'single' LMNCO phase model is used for refinements. For SS$\mathrm{LMNCO}$, the percentage area of the phases (indicative of the phase composition) after refinement was $\sim 65 \%$ and $\sim 35 \%$ for $\mathrm{Li}_{2} \mathrm{MnO}_{3}$ and $\mathrm{LiNi}_{0.33} \mathrm{Mn}_{0.33} \mathrm{Co}_{0.33} \mathrm{O}_{2}$, respectively, indicating an excess of $\mathrm{Li}_{2} \mathrm{MnO}_{3}$, further corroborating the EDX data where the phase was found to be over-represented. That it is also in excess from modelling of the diffraction data implies that the result obtained from EDX is likely applicable to the bulk. SG-LMNCO and SS-LMNCO XRD data were also intentionally fit to the multi- and single-phase models, respectively, to confirm the refinement results. This resulted in chemically invalid models in either case, thereby justifying the initial choice of structure models. Refinement of the structure models against the neutron diffraction data offered further validation of the results, in addition to confirming small amount of $\mathrm{Li}^{+}-\mathrm{Ni}^{2+}$ interlayer mixing in the samples. The refinement process, structure models employed and the refined values are provided in the Supplementary Information sections S6 (X-ray) and S7 (neutron). The results obtained thus far confirms the initial hypothesis that the crystallography of LMNCO is a consequence of synthesis pathway, given the identical composition and heat treatment. To investigate the underlying reasons for these differences, the structures were studied during their synthesis through thermal analysis and in situ powder diffraction.

\section{In situ investigation of the material synthesis}

The thermal gravimetric - differential thermal analysis (TG-DTA) and in situ diffraction data for LMNCO precursors are shown in Fig. 6. As seen in Fig. 6a, the gradual weight loss due to the decomposition of organic matter is all that occurs during the final heating. This suggests that the LMNCO phase must have already formed during the intermediate annealing step. The thermal response of the as-synthesized sol-gel precursor upon heating to $550{ }^{\circ} \mathrm{C}$ (representative of the intermediate heating step) is provided in the SI (Fig. $\mathrm{S} 11)$. The response can be divided into two stages. The first stage centred around $175{ }^{\circ} \mathrm{C}$ arises from the loss of aqueous and acidic species and as the temperature reaches $450{ }^{\circ} \mathrm{C}$, approximately $60 \%$ mass loss has occurred. Between 450 and $500{ }^{\circ} \mathrm{C}$, there is a mass loss of about $35 \%$ due to the decomposition of organic matter and its removal as gaseous products. This decomposition proceeds through breaking of chemical bonds and is highly exothermic. Although in situ diffraction studies are required to understand the crystallization pathway, comparing the ex situ XRD patterns (Fig. 6c) of the intermediate and final SGLMNCO samples, it is clear that the LMNCO phase has already formed after the intermediate heating, with the crystallization happening concomitantly with the organic matter decomposition. Additional reflections in the intermediate sample XRD data (highlighted with asterisks in Fig. 6c inset) indicate that the synthesis is not complete. Superstructure reflections are also already visible in the intermediate sample, signifying some degree of Li-TM ordering. Based on these results, it can be understood that during final annealing step, the crystallinity of the already-formed LMNCO phase increases, together with growth of its crystallites. As the crystallization occurs from a metal-citrate matrix with a homogeneous distribution of cations, the probability for $\mathrm{Mn}$ to preferentially cluster around $\mathrm{Li}$ is reduced, hindering the formation of $\mathrm{Li}_{2} \mathrm{MnO}_{3}$ domains in the structure. In contrast to SS-LMNCO (Fig. 6d inset), the intensity of the $020_{C 2 / m}$ superstructure reflection in the forming SG-LMNCO material does not increase substantially over the course of the final annealing, suggesting an increased kinetic barrier towards Li-TM ordering. 
(a) SG-LMNCO

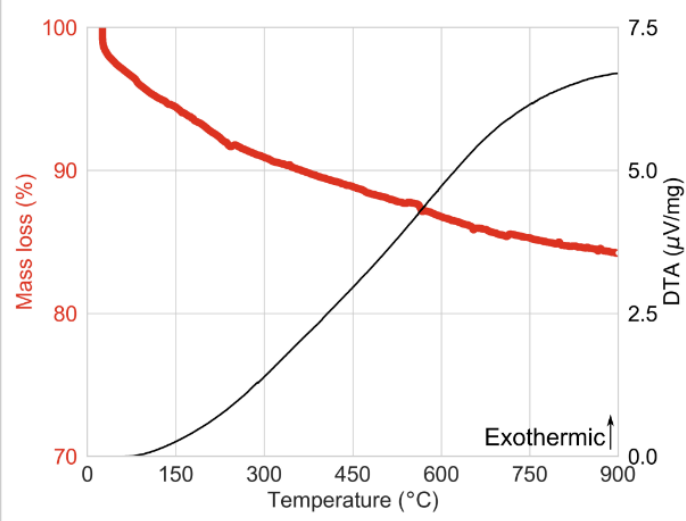

(c)

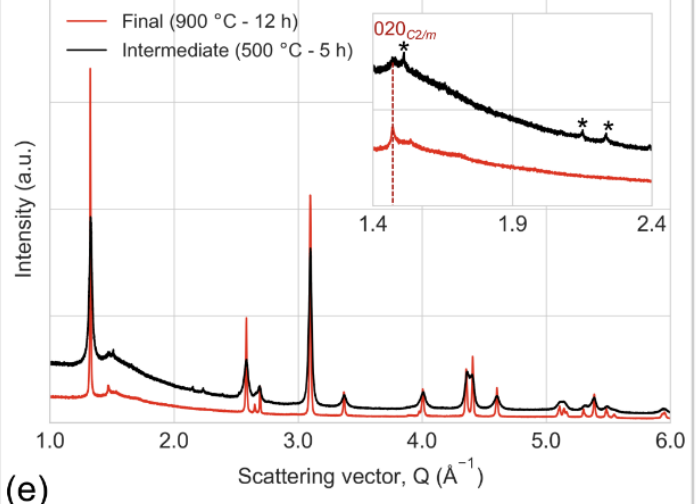

(e)

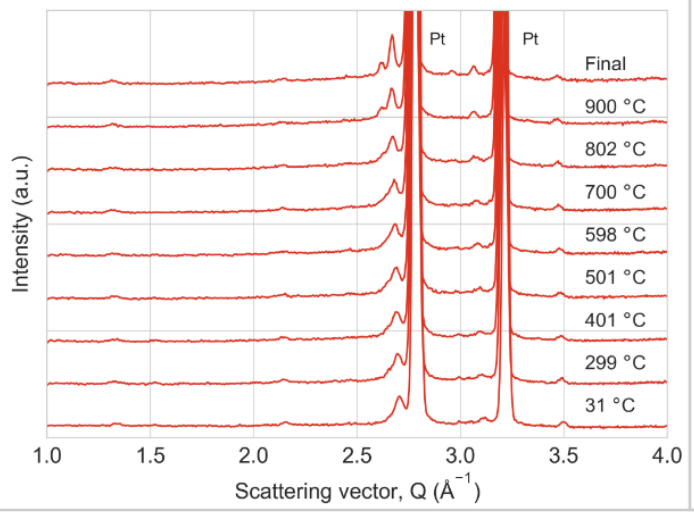

(b) SS-LMNCO

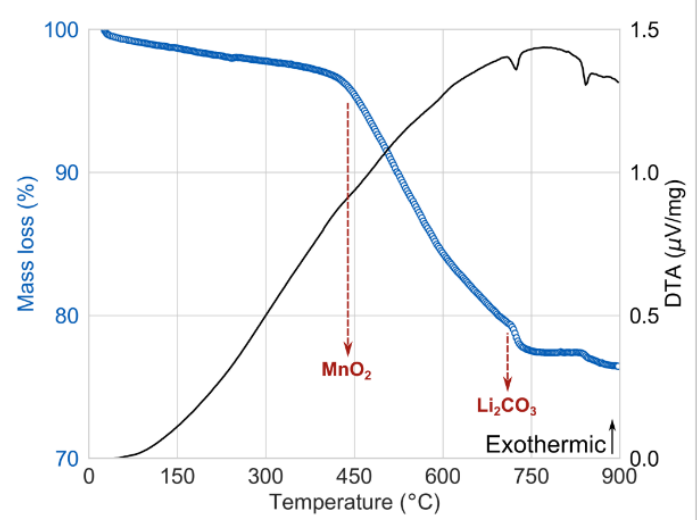

(d)

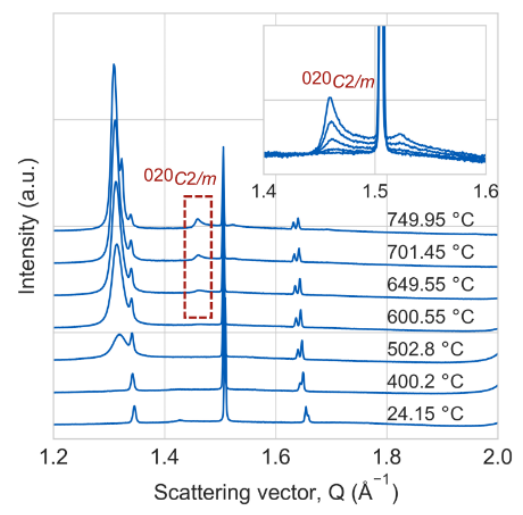

(f)

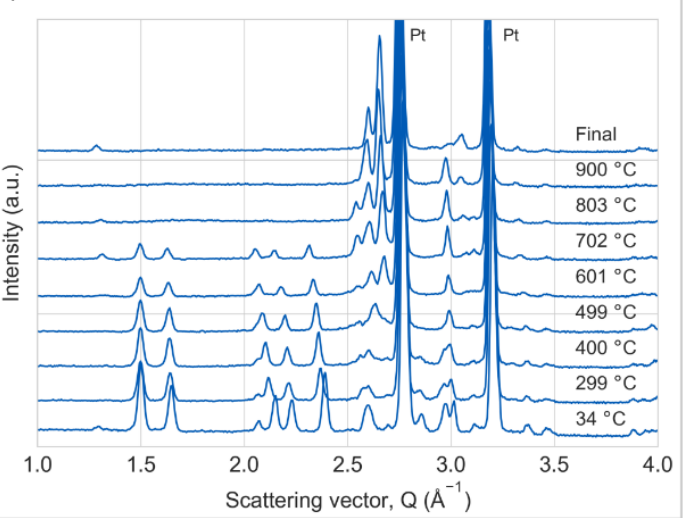

Figure 6: TG-DTA plots of (a) SG-LMNCO and (b) SS-LMNCO precursors. (c) Ex situ XRD data of the SGLMNCO precursor after pre-heating and final annealing. The $020(\mathrm{C} 2 / \mathrm{m})$ superstructure reflection is highlighted in the inset in (c). The asterisk denotes reflections from precursors due to incomplete synthesis reactions. (d) In situ XRD data of the SS-LMNCO precursor at selected temperatures (offset in y), with the 020 reflection highlighted in the inset (plots are overlaid in the inset). In situ NPD data of the (e) SG-LMNCO and (f) SS-LMNCO precursors (offset in $y$ ) at selected temperatures.

Fig. 6b shows the TG-DTA and in situ diffraction data during heating of the SS-LMNCO precursor mix containing $\mathrm{Li}_{2} \mathrm{CO}_{3}, \mathrm{MnO}_{2}, \mathrm{NiO}$, and $\mathrm{Co}_{3} \mathrm{O}_{4}$. Indexed diffraction data of the precursor mix prior to heating are provided in the SI (Figs. S12 and S13). The TG-DTA plots reveal that the synthesis proceeds through three stages corresponding to the decomposition of $\mathrm{MnO}_{2},{ }^{40} \mathrm{Li}_{2} \mathrm{CO}_{3}{ }^{41}$ and $\mathrm{Co}_{3} \mathrm{O}_{4}{ }^{42}$ respectively. The massloss at $\sim 450{ }^{\circ} \mathrm{C}$ corresponds to the onset of the decomposition of $\mathrm{MnO}_{2}$ into $\mathrm{Mn}_{2} \mathrm{O}_{3}$ accompanied by $\mathrm{O}_{2}$ gas 
evolution. The Li-rich phase emerges between 500 and $600{ }^{\circ} \mathrm{C}$, as seen in both the X-ray $\left(001_{C 2 / m}\right.$ at $\sim 1.3$ $\left.\AA^{-1}\right)$ and neutron $\left(131_{C 2 / m}\right.$ and $200_{C 2 / m}$ at $\left.\sim 2.7 \AA^{-1}\right)$ data, and continues to grow with heating. At these temperatures, the $\mathrm{Co}_{3} \mathrm{O}_{4}$ and $\mathrm{NiO}$ reflections are unaffected whereas the intensity of the $\mathrm{Li}_{2} \mathrm{CO}_{3}$ and $\mathrm{MnO}_{2}$ reflections decrease substantially, as shown in the Supplementary Fig. S14, suggesting that the Li-rich phase is $\mathrm{Li}_{2} \mathrm{MnO}_{3}$. Starting at $\sim 620{ }^{\circ} \mathrm{C}$, the $020_{C 2 / m}$ superstructure reflection is clearly seen in the XRD data (Fig. $6 \mathrm{~d}$ inset), evidencing $\mathrm{Li}-\mathrm{Mn}$ ordering in the $\mathrm{Li}_{2} \mathrm{MnO}_{3}$ phase. The asymmetric broadening of these reflections is also clearly visible as they grow, indicating the presence of stacking faults in the $\mathrm{Li}_{2} \mathrm{MnO}_{3}$ phase. As the temperature approaches $700{ }^{\circ} \mathrm{C}$, the $\mathrm{Co}_{3} \mathrm{O}_{4}$ and $\mathrm{NiO}$ reflections begin to lose intensity, indicating their entry into the reaction matrix and on further annealing, the $\mathrm{Ni}$ and $\mathrm{Co}$ species are incorporated into the $\mathrm{Li}_{2} \mathrm{MnO}_{3}$ phase, leading to the formation of the $\mathrm{LMNCO}$ phase. Note that $\mathrm{Li}_{2} \mathrm{CO}_{3}$ is present in the XRD data (at $\sim 1.5$ $\AA^{-1}$ ) at temperatures close to $750{ }^{\circ} \mathrm{C}$, which is higher than its melting point. This is due to the localized (nonuniform) heating of the hot-air blower used for the in situ XRD experiment. However, as seen in the EDX maps, the inhomogeneous contact between the precursors (that leads to varying diffusion lengths) results in the heterogeneous incorporation of $\mathrm{Ni}$ and $\mathrm{Co}$ into the $\mathrm{Li}_{2} \mathrm{MnO}_{3}$ phase. This leads to the formation of $\mathrm{Li}_{2} \mathrm{MnO}_{3}$ and $\mathrm{Li}\left[\mathrm{Ni}_{y} \mathrm{Co}_{z} \mathrm{Mn}_{1-y-z}\right] \mathrm{O}_{2}(y, z \geq 0.33)$ phases that are integrated to varying degrees, ranging from crystallographic intergrowths (within a particle) to instances where they exist as different primary particles. Hence, SS-LMNCO has a multi-phase LMNCO structure that may be represented as $(x) \mathrm{Li}_{2} \mathrm{MnO}_{3} \cdot$ (1$x) \mathrm{Li}\left[\mathrm{Ni}_{y} \mathrm{Co}_{z} \mathrm{Mn}_{1-y-z}\right] \mathrm{O}_{2}$ where $0.5 \leq x \leq 1$ and $y, z \geq 0.33$. Considering the above mechanism, it is clear that the specific crystallization pathway of SS-LMNCO will be dependent on the choice of precursors and temperatures at which they begin to react. This offers additional possibilities through which the crystallography can be controlled.

The differences in synthesis routes is also reflected in the degree of faulting observed in the samples. The reduced stacking disorder in SS-LMNCO indicates increased periodicity in Li-Mn layer along the $c$ direction in the $\mathrm{Li}_{2} \mathrm{MnO}_{3}$ phase. This is achieved as the cation ordering involves only two species ( $\mathrm{Li}$ and $\mathrm{Mn}$ ) and, therefore, order between consecutive TM layers is thermodynamically favourable relative to SG-LMNCO, where four cations ( $\mathrm{Li}$ with $\mathrm{Mn}, \mathrm{Ni}$, and $\mathrm{Co}$ ) are involved. This imparts more degrees of freedom and entropically drives SG-LMNCO towards a more disordered state. Additionally, the presence of organic matter may hinder the formation of a well-layered structure, as shown for sol-gel synthesized $\mathrm{Li}_{2} \mathrm{MnO}_{3}$ in our previous work. ${ }^{16}$

This work establishes that the phase composition of LMNCO varies significantly depending on the synthetic route. The LMNCO samples of this work were synthesized using limited heat treatment protocols, and thus both structural forms could be metastable. This leads to questions concerning the most thermodynamically stable LMNCO configuration and its formation mechanism. Are there thermodynamic drivers for phase segregation or does entropy-stabilisation driven by configurational disorder lead to solid solution - like single-phase structures ${ }^{43}$ ? This is an important consequence of the present study to consider when tailoring the design of electrode materials as different metastable configurations will result in different electrochemical responses. Furthermore, the anionic redox behaviour of LMNCO has been explained based on the $\mathrm{Li}_{2} \mathrm{MnO}_{3}$ domains in the structure in several studies. ${ }^{12,44,45}$ However, the single-phase SG-LMNCO (without $\mathrm{Li}_{2} \mathrm{MnO}_{3}$ domains) show electrochemical and anionic redox behaviour that is typical of LMNCO systems (Supplementary Fig. S15). This reveals that the anionic redox behaviour is not dependent on the presence of $\mathrm{Li}_{2} \mathrm{MnO}_{3}$ domains. 


\section{Conclusion}

This work demonstrates that $\mathrm{Li}_{1.2} \mathrm{Mn}_{0.54} \mathrm{Ni}_{0.13} \mathrm{Co}_{0.13} \mathrm{O}_{2}$ (LMNCO) can exist in multiple non-equilibrium crystallographic forms, with the synthesis route being a major determinant. The solid-state synthesized LMNCO (SS-LMNCO) crystallizes as a multi-phase structure, with $\mathrm{Li}_{2} \mathrm{MnO}_{3}$ and $\mathrm{Li}\left[\mathrm{Ni}_{y} \mathrm{Co}_{z} \mathrm{Mn}_{1-y-z}\right] \mathrm{O}_{2}(y, z$ $\geq 0.33$ ) phases integrated to varying degrees ranging from crystallographic intergrowths to distinct particles. This is a consequence of the synthetic pathway, where the initial reaction between the $\mathrm{Li}_{2} \mathrm{CO}_{3}$ and $\mathrm{MnO}_{2}$ precursors forms $\mathrm{Li}_{2} \mathrm{MnO}_{3}$, after which $\mathrm{Co}$ and $\mathrm{Ni}$ are integrated into the structure heterogeneously resulting in $\mathrm{Li}\left[\mathrm{Ni}_{y} \mathrm{Co}_{z} \mathrm{Mn}_{1-y-z}\right] \mathrm{O}_{2}(y, z \geq 0.33)$ phases. The sol-gel synthesized sample (SG-LMNCO) on the other hand, has a single-phase structure with a homogeneous distribution of transition metal (TM) with respect to $\mathrm{Li}$ in the TM layer. Here, $\mathrm{Li}_{2} \mathrm{MnO}_{3}$ domains do not form as the LMNCO phase crystallizes from a metal-citrate matrix where the cations are uniformly distributed. It is envisaged that these results clarify the structural ambiguities of this promising electrode material and in doing so, pave the way for further advancement of Li- and Mn-rich layered oxides. This work also accentuates the need for extra caution and complementary techniques during the structural characterization of novel complex materials, where the local structural and configurational (dis)order can lead to multiple metastable states entirely dependent on the synthetic route. 


\section{Funding Sources}

This research is funded by the Swedish Foundation for Strategic Research (SSF) within the Swedish national graduate school in neutron scattering (SwedNess). The authors also gratefully acknowledge funding from the Strategic Research Area StandUp for Energy and the Swedish Energy Agency. The Swedish research council, VR, is also acknowledged (Grant Nos: 349-2014-3946 and 2016-06959).

\section{Acknowledgments}

The authors are grateful to Dr. Anita D'Angelo (Beamline scientist), at the Powder Diffraction beamline, Australian Synchrotron as well as Dr. Chiu Tang (principal beamline scientist) and Dr. Stephen Thompson (senior beamline scientist) at the I11 High Resolution Powder Diffraction beamline at the Diamond Light Source (UK) for their help and guidance. The powder diffraction beamlines and sample environment team at ANSTO, Sydney are also acknowledged. A.S.M is particularly grateful to colleagues Victor Pacheco, Dr. Adriano Francesco Pavan and Dr. Ronnie Mogensen for their support and help.

\section{Competing Interests}

The authors declare no competing financial interest. 


\section{$\underline{\text { References }}$}

1. Hu, S.; Pillai, A. S.; Liang, G.; Pang, W. K.; Wang, H.; Li, Q.; Guo, Z., Li-Rich Layered Oxides and Their Practical Challenges: Recent Progress and Perspectives. Electrochemical Energy Reviews 2019, 135 .

2. Assat, G.; Foix, D.; Delacourt, C.; Iadecola, A.; Dedryvère, R.; Tarascon, J.-M., Fundamental interplay between anionic/cationic redox governing the kinetics and thermodynamics of lithium-rich cathodes. Nature Communications 2017, 8 (1), 2219.

3. Kleiner, K.; Strehle, B.; Baker, A. R.; Day, S. J.; Tang, C. C.; Buchberger, I.; Chesneau, F.-F.; Gasteiger, H. A.; Piana, M., Origin of High Capacity and Poor Cycling Stability of Li-Rich Layered Oxides: A Long-Duration in Situ Synchrotron Powder Diffraction Study. Chemistry of Materials 2018, 30 (11), 3656-3667.

4. Eum, D.; Kim, B.; Kim, S. J.; Park, H.; Wu, J.; Cho, S.-P.; Yoon, G.; Lee, M. H.; Jung, S.-K.; Yang, W.; Seong, W. M.; Ku, K.; Tamwattana, O.; Park, S. K.; Hwang, I.; Kang, K., Voltage decay and redox asymmetry mitigation by reversible cation migration in lithium-rich layered oxide electrodes. Nature Materials 2020, 19 (4), 419-427.

5. Cui, C.; Fan, X.; Zhou, X.; Chen, J.; Wang, Q.; Ma, L.; Yang, C.; Hu, E.; Yang, X.-Q.; Wang, C., Structure and Interface Design Enable Stable Li-Rich Cathode. Journal of the American Chemical Society 2020, 142 (19), 8918-8927.

6. Zhang, P.; Zhai, X.; Huang, H.; Zhou, J.; Li, X.; He, Y.; Guo, Z., Suppression of structural phase transformation of Li-rich Mn-based layered cathode materials with $\mathrm{Na}$ ion substitution strategy. Electrochimica Acta 2020, 349, 136402.

7. Shukla, A. K.; Ramasse, Q. M.; Ophus, C.; Duncan, H.; Hage, F.; Chen, G., Unravelling structural ambiguities in lithium- and manganese-rich transition metal oxides. Nature Communications 2015, 6 , 8711.

8. Koga, H.; Croguennec, L.; Mannessiez, P.; Ménétrier, M.; Weill, F.; Bourgeois, L.; Duttine, M.; Suard, E.; Delmas, C., $\mathrm{Li}_{1.20} \mathrm{Mn}_{0.54} \mathrm{Co}_{0.13} \mathrm{Ni}_{0.13} \mathrm{O}_{2}$ with Different Particle Sizes as Attractive Positive Electrode Materials for Lithium-Ion Batteries: Insights into Their Structure. The Journal of Physical Chemistry C 2012, 116 (25), 13497-13506.

9. Boulineau, A.; Croguennec, L.; Delmas, C.; Weill, F., Reinvestigation of Li2MnO3 Structure: Electron Diffraction and High Resolution TEM. Chemistry of Materials 2009, 21 (18), 4216-4222. 10. Yin, S. C.; Rho, Y. H.; Swainson, I.; Nazar, L. F., X-ray/Neutron Diffraction and Electrochemical Studies of Lithium De/Re-Intercalation in $\mathrm{Li}_{1-\mathrm{x}} \mathrm{Co}_{1 / 3} \mathrm{Ni}_{1 / 3} \mathrm{Mn}_{1 / 3} \mathrm{O}_{2}(\mathrm{x}=0 \rightarrow 1)$. Chemistry of Materials 2006, 18 (7), 1901-1910.

11. Yu, H.; Ishikawa, R.; So, Y.-G.; Shibata, N.; Kudo, T.; Zhou, H.; Ikuhara, Y., Direct AtomicResolution Observation of Two Phases in the $\mathrm{Li}_{1.2} \mathrm{Mn}_{0.567} \mathrm{Ni}_{0.166} \mathrm{Co}_{0.067} \mathrm{O}_{2}$ Cathode Material for Lithium-Ion Batteries. 2013, 125 (23), 6085-6089.

12. Thackeray, M. M.; Kang, S.-H.; Johnson, C. S.; Vaughey, J. T.; Benedek, R.; Hackney, S. A., $\mathrm{Li}_{2} \mathrm{MnO}_{3}$-stabilized $\mathrm{LiMO}_{2}(\mathrm{M}=\mathrm{Mn}, \mathrm{Ni}, \mathrm{Co})$ electrodes for lithium-ion batteries. Journal of Materials Chemistry 2007, 17 (30), 3112-3125.

13. Mohanty, D.; Huq, A.; Payzant, E. A.; Sefat, A. S.; Li, J.; Abraham, D. P.; Wood, D. L.; Daniel, C., Neutron Diffraction and Magnetic Susceptibility Studies on a High-Voltage Li1.2Mn0.55Ni0.15Co0.10O2Lithium Ion Battery Cathode: Insight into the Crystal Structure. Chemistry of Materials 2013, 25 (20), 4064-4070.

14. Whitfield, P.; Davidson, I.; Stephens, P.; Cranswick, L.; Swainson, I., Diffraction analysis of the lithium battery. Z. Kristallogr 2007, 26, 483-488.

15. Warren, B. E., X-Ray Diffraction in Random Layer Lattices. Physical Review 1941, 59 (9), 693-698.

16. Menon, A. S.; Ojwang, D. O.; Willhammar, T.; Peterson, V. K.; Edström, K.; Gomez, C. P.; Brant, W. R., Influence of Synthesis Routes on the Crystallography, Morphology, and Electrochemistry of $\mathrm{Li}_{2} \mathrm{MnO}_{3}$. ACS Applied Materials \& Interfaces 2020, 12 (5), 5939-5950. 
17. Leifer, N.; Penki, T. R.; Nanda, R.; Grinblat, J.; Luski, S.; Aurbach, D.; Goobes, G., Linking Structure to Performance of $\mathrm{Li}_{1.2} \mathrm{Mn}_{0.54} \mathrm{Ni}_{0.13} \mathrm{Co}_{0.13} \mathrm{O}_{2}$ ( $\mathrm{Li}$ and $\mathrm{Mn}$ rich NMC) Cathode Materials Synthesized by Different Methods. Physical Chemistry Chemical Physics 2020, 22(16), 9098-9109. 18. Xiang, Y.; Yin, Z.; Zhang, Y.; Li, X., Effects of synthesis conditions on the structural and electrochemical properties of the Li-rich material $\mathrm{Li}\left[\mathrm{Li}_{0.2} \mathrm{Ni}_{0.17} \mathrm{Co}_{0.16} \mathrm{Mn}_{0.47}\right] \mathrm{O}_{2}$ via the solid-state method. Electrochimica Acta 2013, 91 (Supplement C), 214-218.

19. Riekehr, L.; Liu, J.; Schwarz, B.; Sigel, F.; Kerkamm, I.; Xia, Y.; Ehrenberg, H., Effect of pristine nanostructure on first cycle electrochemical characteristics of lithium-rich lithium-nickel-cobaltmanganese-oxide cathode ceramics for lithium ion batteries. Journal of Power Sources 2016, 306, 135147.

20. Rao, C. N. R., Chemical synthesis of solid inorganic materials. Materials Science and Engineering: $B$ 1993, $18(1), 1-21$.

21. Pechini, M. P. Method of preparing lead and alkaline earth titanates and niobates and coating method using the same to form a capacitor. 3,330,697, 1967.

22. Wallwork, K. S.; Kennedy, B. J.; Wang, D., The High Resolution Powder Diffraction Beamline for the Australian Synchrotron. AIP Conference Proceedings 2007, 879 (1), 879-882.

23. Avdeev, M.; Hester, J. R., ECHIDNA: a decade of high-resolution neutron powder diffraction at OPAL. Journal of Applied Crystallography 2018, 51 (6), 1597-1604.

24. Thompson, S. P.; Parker, J. E.; Potter, J.; Hill, T. P.; Birt, A.; Cobb, T. M.; Yuan, F.; Tang, C. C., Beamline I1 1 at Diamond: A new instrument for high resolution powder diffraction. Review of Scientific Instruments 2009, 80 (7), 075107.

25. Studer, A. J.; Hagen, M. E.; Noakes, T. J., Wombat: The high-intensity powder diffractometer at the OPAL reactor. Physica B: Condensed Matter 2006, 385-386, 1013-1015.

26. Pawley, G., Unit-cell refinement from powder diffraction scans. Journal of Applied Crystallography 1981, 14 (6), 357-361.

27. Coelho, A., TOPAS and TOPAS-Academic: an optimization program integrating computer algebra and crystallographic objects written in C++. Journal of Applied Crystallography 2018, 51 (1), 210-218. 28. Rietveld, H. M., Line profiles of neutron powder-diffraction peaks for structure refinement. Acta Crystallographica 1967, 22 (1), 151-152.

29. Rietveld, H., A profile refinement method for nuclear and magnetic structures. Journal of Applied Crystallography 1969, 2 (2), 65-71.

30. Casas-Cabanas, M.; Reynaud, M.; Rikarte, J.; Horbach, P.; Rodriguez-Carvajal, J., FAULTS: a program for refinement of structures with extended defects. Journal of Applied Crystallography 2016, 49 (6), 2259-2269.

31. Serrano-Sevillano, J.; Reynaud, M.; Saracibar, A.; Altantzis, T.; Bals, S.; Van Tendeloo, G.; CasasCabanas, M., Enhanced electrochemical performance of Li-rich cathode materials through microstructural control. Physical Chemistry Chemical Physics 2018.

32. Momma, K.; Izumi, F., VESTA: a three-dimensional visualization system for electronic and structural analysis. Journal of Applied Crystallography 2008, 41 (3), 653-658.

33. Virtanen, P.; Gommers, R.; Oliphant, T. E.; Haberland, M.; Reddy, T.; Cournapeau, D.; Burovski, E.; Peterson, P.; Weckesser, W.; Bright, J.; van der Walt, S. J.; Brett, M.; Wilson, J.; Millman, K. J.; Mayorov, N.; Nelson, A. R. J.; Jones, E.; Kern, R.; Larson, E.; Carey, C. J.; Polat, İ; Feng, Y.; Moore, E. W.; VanderPlas, J.; Laxalde, D.; Perktold, J.; Cimrman, R.; Henriksen, I.; Quintero, E. A.; Harris, C. R.; Archibald, A. M.; Ribeiro, A. H.; Pedregosa, F.; van Mulbregt, P.; Vijaykumar, A.; Bardelli, A. P.; Rothberg, A.; Hilboll, A.; Kloeckner, A.; Scopatz, A.; Lee, A.; Rokem, A.; Woods, C. N.; Fulton, C.; Masson, C.; Häggström, C.; Fitzgerald, C.; Nicholson, D. A.; Hagen, D. R.; Pasechnik, D. V.; Olivetti, E.; Martin, E.; Wieser, E.; Silva, F.; Lenders, F.; Wilhelm, F.; Young, G.; Price, G.

A.; Ingold, G.-L.; Allen, G. E.; Lee, G. R.; Audren, H.; Probst, I.; Dietrich, J. P.; Silterra, J.; Webber, J. T.; Slavič, J.; Nothman, J.; Buchner, J.; Kulick, J.; Schönberger, J. L.; de Miranda Cardoso, J. V.; Reimer, J.; Harrington, J.; Rodríguez, J. L. C.; Nunez-Iglesias, J.; Kuczynski, J.; Tritz, K.; Thoma, M.; Newville, M.; Kümmerer, M.; Bolingbroke, M.; Tartre, M.; Pak, M.; Smith, N. J.; Nowaczyk, N.; 
Shebanov, N.; Pavlyk, O.; Brodtkorb, P. A.; Lee, P.; McGibbon, R. T.; Feldbauer, R.; Lewis, S.; Tygier, S.; Sievert, S.; Vigna, S.; Peterson, S.; More, S.; Pudlik, T.; Oshima, T.; Pingel, T. J.; Robitaille, T. P.; Spura, T.; Jones, T. R.; Cera, T.; Leslie, T.; Zito, T.; Krauss, T.; Upadhyay, U.; Halchenko, Y. O.; Vázquez-Baeza, Y.; SciPy, C., SciPy 1.0: fundamental algorithms for scientific computing in Python. Nature Methods 2020, 17 (3), 261-272.

34. Xiao, J.; Chernova, N. A.; Whittingham, M. S., Layered Mixed Transition Metal Oxide Cathodes with Reduced Cobalt Content for Lithium Ion Batteries. Chemistry of Materials 2008, 20 (24), 7454-7464.

35. Greedan, J. E., Geometrically frustrated magnetic materials. Journal of Materials Chemistry 2001, 11 (1), 37-53.

36. Chernova, N. A.; Ma, M.; Xiao, J.; Whittingham, M. S.; Breger, J.; Grey, C. P., Layered $\mathrm{Li}_{\mathrm{x}} \mathrm{Ni}_{\mathrm{y}} \mathrm{Mn}_{\mathrm{y}} \mathrm{Co}_{1-2 \mathrm{y}} \mathrm{O}_{2}$ Cathodes for Lithium Ion Batteries: Understanding Local Structure via Magnetic Properties. Chemistry of Materials 2007, 19 (19), 4682-4693.

37. Julien, C. M.; Ait-Salah, A.; Mauger, A.; Gendron, F., Magnetic properties of lithium intercalation compounds. Ionics 2006, 12 (1), 21-32.

38. Fertman, E.; Dolya, S.; Desnenko, V.; Beznosov, A.; Kajňaková, M.; Feher, A., Cluster glass magnetism in the phase-separated $\mathrm{Nd}_{2 / 3} \mathrm{Ca}_{1 / 3} \mathrm{MnO}_{3}$ perovskite. Journal of Magnetism and Magnetic Materials 2012, 324 (19), 3213-3217.

39. Goodenough, J. B., Direct Cation- -Cation Interactions in Several Oxides. Physical Review 1960, 117 (6), 1442-1451.

40. Terayama, K.; Ikeda, M., Study on thermal decomposition of $\mathrm{MnO}_{2}$ and $\mathrm{Mn}_{2} \mathrm{O}_{3}$ by thermal analysis. Transactions of the Japan institute of metals 1983, 24 (11), 754-758.

41. Kim, J.-W.; Lee, H.-G., Thermal and carbothermic decomposition of $\mathrm{Na}_{2} \mathrm{CO}_{3}$ and $\mathrm{Li}_{2} \mathrm{CO}_{3}$. Metallurgical and Materials Transactions B 2001, 32 (1), 17-24.

42. Chen, M.; Hallstedt, B.; Gauckler, L. J., Thermodynamic assessment of the Co-O system. Journal of Phase Equilibria 2003, 24 (3), 212-227.

43. Lun, Z.; Ouyang, B.; Kwon, D.-H.; Ha, Y.; Foley, E. E.; Huang, T.-Y.; Cai, Z.; Kim, H.;

Balasubramanian, M.; Sun, Y.; Huang, J.; Tian, Y.; Kim, H.; McCloskey, B. D.; Yang, W.; Clément, R. J.; Ji, H.; Ceder, G., Cation-disordered rocksalt-type high-entropy cathodes for Li-ion batteries. Nature Materials 2020.

44. Yu, H.; So, Y.-G.; Ren, Y.; Wu, T.; Guo, G.; Xiao, R.; Lu, J.; Li, H.; Yang, Y.; Zhou, H.; Wang, R.; Amine, K.; Ikuhara, Y., Temperature-Sensitive Structure Evolution of Lithium-Manganese-Rich Layered Oxides for Lithium-Ion Batteries. Journal of the American Chemical Society 2018, 140 (45), 15279-15289.

45. Chen, C.-J.; Pang, W. K.; Mori, T.; Peterson, V. K.; Sharma, N.; Lee, P.-H.; Wu, S.-h.; Wang, C.C.; Song, Y.-F.; Liu, R.-S., The Origin of Capacity Fade in the $\mathrm{Li}_{2} \mathrm{MnO}_{3} \cdot \mathrm{LiMO}_{2}(\mathrm{M}=\mathrm{Li}, \mathrm{Ni}, \mathrm{Co}, \mathrm{Mn})$ Microsphere Positive Electrode: An Operando Neutron Diffraction and Transmission X-ray Microscopy Study. Journal of the American Chemical Society 2016, 138 (28), 8824-8833. 